\title{
INFLUENCE OF LASER CUTTING ON THE FATIGUE LIMIT OF TWO HIGH STRENGTH STEELS
}

\author{
A. Mateo ${ }^{1)}$, G. Fargas ${ }^{1)}$, J. Calvo ${ }^{1-2)}$, J.J. Roa ${ }^{1)}$ \\ ${ }^{1)}$ Department of Materials Science and Metallurgical Engineering, \\ Universitat Politècnica de Catalunya, Avda. Diagonal 647, 08028 Barcelona, Spain \\ ${ }^{2)}$ Fundació CTM Centre Tecnològic, Av. Bases de Manresa 1, \\ 08242 Manresa, Barcelona, Spain
}

\begin{abstract}
Laser cutting is widely used in the metal industry, particularly when components of high strength steels sheets are produced. On the other hand, the roughness of cut-edges produced by laser differs from that obtained by other methods, such as mechanical blanking, and this fact influences the fatigue performance. Moreover, thermal effects are another factor to consider.

In the present investigation, specimens of two grades of high strength austenitic steels were cut by laser and tested in the high cycle fatigue regime to determine their corresponding fatigue limits. One of the steels was a metastable stainless grade (AISI 301LN) whereas the other corresponded to the TWIP family (TWIP17Mn). Load control fatigue testing was conducted at a stress ratio $\mathrm{R}$ of 0.1 and using the stair-case methodology. A series of fatigue specimens were tested without polishing the cut-edges and other series after a careful polishing, in order to assess the influence of the cut-edges condition. Results indicate a significant influence of the edges roughness, more marked for the AISI 301LN than for the TWIP steel. In the latter material, the presence of nitrides induced a premature fatigue crack nucleation.
\end{abstract}

\section{KEYWORDS}

Fatigue limit, metastable stainless steel, TWIP steel, laser cutting, cut-edges.

\section{INTRODUCTION}

The automotive industry is the second largest steel market after construction and public works. Chassis, body, engine parts, steering, transmission and exhaust system, etc., are made of steel, so it represents about $70 \%$ of the weight of the body-in-white (BIW) of an ordinary car. Automotive companies are trying to develop lighter vehicles because lower weight is mandatory in order to achieve a reduction in fuel consumption and also a diminution of contaminant emissions. However, at the same time, these companies are forced to increase safety levels, particularly in crash tests conditions, and to maintain standards of comfort required by customers [1]. Encouraged by these needs of the automotive industry, the steel manufacturers have developed in the last decades a new grade of steels known as High Strength Steels (HSS). 
Figure 1 shows the advent of another generation of steels: the Advanced High-Strength Steels (AHSS). First generation AHSS includes, among others, dual phase (DP), transformation induced plasticity (TRIP), complex phase (CP) and martensitic stels. Second generation AHSS (blue globus in Fig. 1) combine high strenght with excellent ductility. This generation includes twinning induced plasticity (TWIP) steels, Al-added lightweight steels with induced plasticity (L-IP) and metastable austenitic stainless steels. Nowadays, there is an increasing interest in the development of a "Third Generation" of AHSS, i.e. steels with strength-ductility combinations significantly better than exhibited by the steels of the first generation but at a cost significantly lower than the second generation ones.

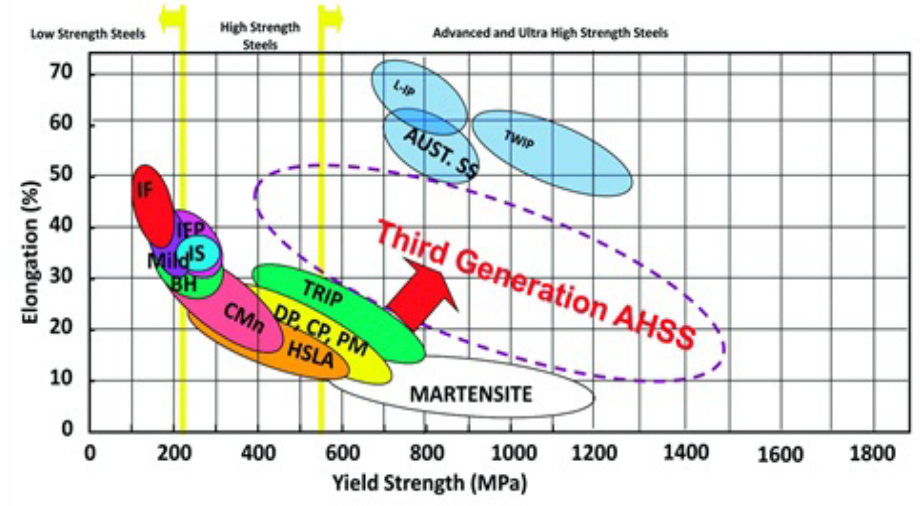

Fig.1: Tensile elongation versus yield strength for different LSS (Low Strength Steels), HSS (High Strength Steels) and AHSS (Advanced High Strength Steels) grades [2].

Different types of cutting methods are used in the sheet metal industry. The selection between them can be based in factors such as tolerances, price, availability, etc.. The elevated mechanical resistance of AHSS makes more difficult the conventional cutting by shearing. For that reason, laser cutting offers a desirable alternative to mechanical blanking, due to its capability to cut sheet components of AHSS with intricate geometries at high precision, combined with speed and flexibility [3].

Cut-edges of steel sheets produced by laser differ from mechanically cut ones in topography, residual stresses and microstructural changes induced by heat exposition. These factors determine the edges quality, which becomes a critical factor if the component has to be exposed to fatigue loading during its service life. Literature works indicate that laser cutedges of AHSS tend to display improved fatigue strength in comparison with mechanical cutedges. Meurling et al. [4] attributed this fact to the larger number of accumulated defects on the surface of mechanical cut-edge fracture zones in comparison with those of laser cut-edge surfaces. On the other hand, Thomas et al. [3] showed that slight variations in laser power and cutting speed may result in non-optimum process parameters, which significantly increase the cut-edge roughness.

The present paper addresses the influence of the cut-edges quality produced by laser on the fatigue limit of two types of second generation AHSS. In order to assess this influence, some fatigue specimens were tested in the as-received state after laser cutting, i.e. without polishing the laser cut-edges, and others after a careful polishing of them.

\section{MATERIALS}

Two grades of second generation AHSS were used in this investigation: a metastable stainless (AISI 301LN) and a TWIP steel (TWIP17Mn). Their chemical compositions are given in Table 1. 


\begin{tabular}{|c|c|c|c|c|c|c|c|c|c|c|c|}
\hline Steel & $\mathbf{C}$ & $\mathbf{C r}$ & $\mathbf{N i}$ & $\mathbf{M n}$ & $\mathbf{A l}$ & $\mathbf{S i}$ & $\mathbf{M o}$ & $\mathbf{N}$ & $\mathbf{T i}$ & $\mathbf{P}$ & $\mathbf{S}$ \\
\hline 301LN & 0.029 & 17.45 & 7.08 & 1.27 & 0.005 & 0.52 & 0.15 & 0.14 & 0.006 & 0.058 & 0.003 \\
\hline TWIP17Mn & 0.722 & 0.035 & 0.14 & 16.76 & 1.922 & 0.07 & 0.34 & - & 0.096 & 0.018 & 0.015 \\
\hline
\end{tabular}

Table 1. Chemical composition of the two steels tested (in weight \%).

The AISI 301 LN stainless steel (equivalent to standard EN 1.4318), used in this study was a commercial grade fabricated by Outokumpu (Finland). It was supplied as $1.5 \mathrm{~mm}$ thick sheets produced by cold rolling, annealing, pickling and a final skin passing. AISI 301LN is considered to be metastable since its austenitic microstructure transforms to $\alpha^{\prime}$-martensite when it is plastically deformed. Metastable stainless steels are currently used in applications where corrosion resistance is required in combination with versatile mechanical properties. In the annealed state, their totally austenitic microstructure confers them an excellent ductility although limited yield stress. Cold deformation generates strain-induced martensite which, in addition to austenite strain hardening, results in a drastic improvement of yield stress [5] besides an excellent formability.

On the other hand, TWIP17Mn was produced by Posco (South Corea) as $1.5 \mathrm{~mm}$ thick sheets. TWIP steels contain ultra-high manganese (until 25\%) that renders the austenite totally stable, so it does not transform during the deformation. The high plasticity is obtained by twinning and not by austenite transformation to martensite. As the formation of deformation twins involves the creation of new crystal orientations, twins progressively reduce the effective mean free path of dislocations and increase the flow stress, resulting in an ultra-high strain hardening [6].

In metastable steels, mechanical grinding and polishing can induce transformations on the surface layer. To avoid this effect, electro-polishing with $65 \%$ nitric acid solution was carried out at $12 \mathrm{~V}$. For the stainless steel, samples were electro-etched in the same polishing solution, whereas Nital6 was used for TWIP.

Figure 2 shows optical microscopy images of both steels. Microstructures were composed of equiaxial austenitic grains, with an average grain size of $15.3 \pm 7.0 \mu \mathrm{m}$ for $301 \mathrm{LN}$ and $4.8 \pm$ $1.9 \mu \mathrm{m}$ for TWIP. X-ray diffraction spectra confirmed the absence of martensite.
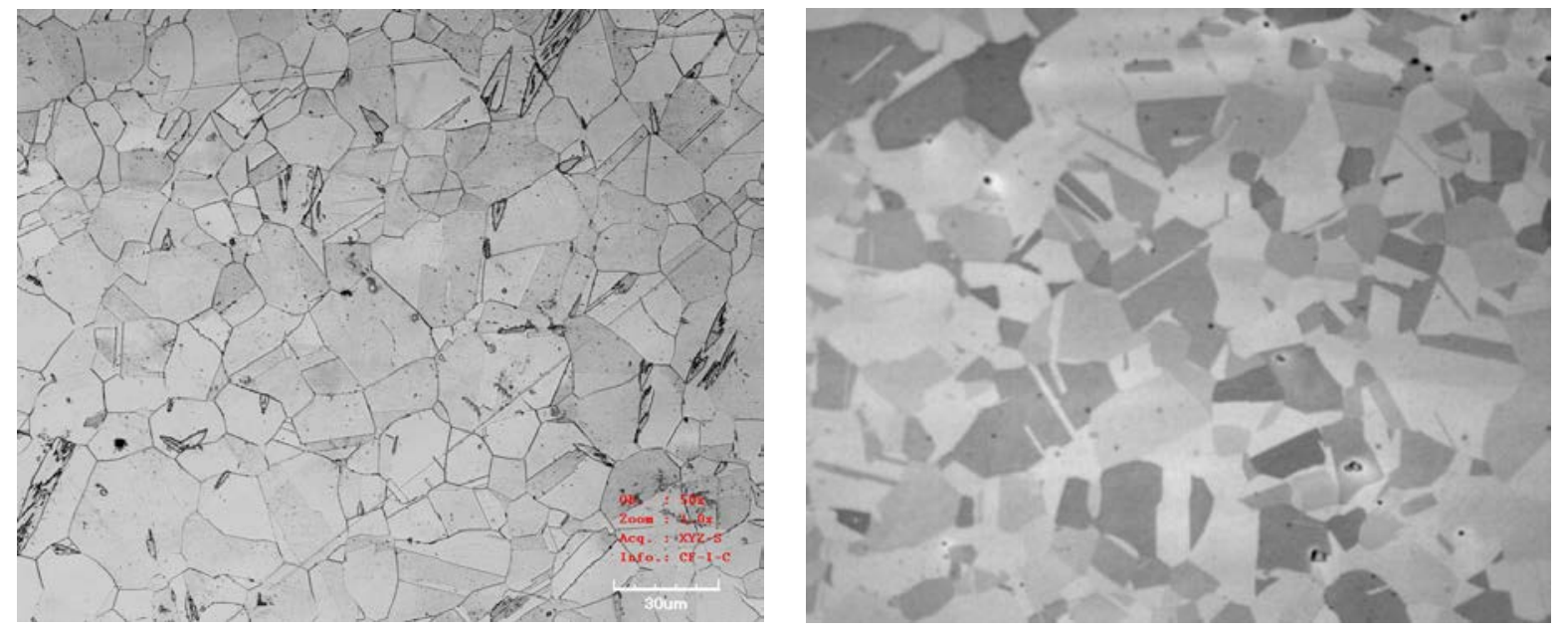

Fig 2. Optical micrographs of:

(a) AISI 301LN;

(b) TWIP17Mn. 


\section{FATIGUE TESTING}

A pulsed Nd:YAG laser working at $60 \mathrm{~Hz}$, with a maximum power of $200 \mathrm{~W}$ and a cutting speed of $160 \mathrm{~mm} / \mathrm{min}$ was used to machine flat fatigue specimens with hour-glass shape (3.8 mm of minimum width) from the sheets. Their thickness was that of the sheets and their load axis always was coincident with the rolling direction. Whether these laser process conditions are compared with other literature works [3], they can be classified as low power and very slow cutting speed.

To establish the fatigue testing loads, the static properties of the investigated steels were first determined. Tensile tests were performed at a crosshead rate of $3 \mathrm{~mm} / \mathrm{min}$. Table 2 presents the results, where the high strength and excellent ductility of both steels are patent.

\begin{tabular}{|c|c|c|c|}
\hline Steel grade & $\begin{array}{c}\text { Yield stress, } \\
\sigma_{\mathrm{ys}} \text { (MPa) }\end{array}$ & $\begin{array}{c}\text { Tensile strength, } \\
\sigma_{\text {uts }}(\mathrm{MPa})\end{array}$ & $\begin{array}{c}\text { Elongation to } \\
\text { fracture (\%) }\end{array}$ \\
\hline 301LN & 410 & 905 & 55 \\
\hline TWIP17Mn & 495 & 980 & 60 \\
\hline
\end{tabular}

Table 2. Tensile properties of the investigated steels.

Considering these tensile characteristics, a fatigue testing procedure based in the staircase (or up-and-down) method was applied to determine the fatigue limits [7]. It consisted on starting the tests sequence applying a maximum load $\left(\sigma_{\max }\right)$ around $55 \%$ of the ultimate tensile strength of the corresponding steel. If the specimen failed before infinite life (say $2 \times 10^{6}$ cycles), the next specimen had to be tested at a $5 \%$ lower stress level. If the specimen did not fail, the next test was run with the same specimen at a higher stress level, and so on until its fracture. Despite it is recommended to run the staircase with at least 15 specimens, a more reduced number (nearby 8 per condition) were used for this research. Tests were conducted in a resonant testing machine at frequencies around $150 \mathrm{~Hz}$ with a stress ratio $\left(R=\sigma_{\min } / \sigma_{\max }\right)$ of 0.1 .

To assess the influence of the cut-edges produced by laser on the fatigue limit of both steels, two series of tests were performed for each one. A first series of fatigue specimens were tested in the as-cut state, without polishing the edges. Previously, the roughness of these edges had been measured with an optical interferometric profiler, giving $R_{a}$ values of $3.0 \pm$ $0.2 \mu \mathrm{m}$ for $301 \mathrm{LN}$ and $5.3 \pm 1.3 \mu \mathrm{m}$ for TWIP. A second series of specimens were carefully polished, first mechanically and as last step by electro-polishing, up to $R_{a}$ values of $0.6 \pm 0.3$ $\mu \mathrm{m}$ for both steels. Afterwards, those specimens were tested following the same methodology than for the first series.

\section{RESULTS AND DISCUSSION}

Figure 3 shows the wavy aspect of the edges of fatigue specimens after laser cutting. This aspect was qualitatively similar for the two studied steels. The laser beam produces a pattern of striations, which is due to overlaps of molten steel deposited as wavy features. Two different parts can be discerned in Fig. 3: from the top side and up to 2/3 of the thickness, a more irregular surface is created by the entrance of the laser beam, whereas the down side exhibits a more regular sequence of striations. 
The fatigue limits obtained following the staircase procedures previously commented are given in Table 3 in terms of both maximum stress $\left(\sigma_{\mathrm{f}, \max }\right)$ and stress amplitude $(\Delta \sigma / 2)$.

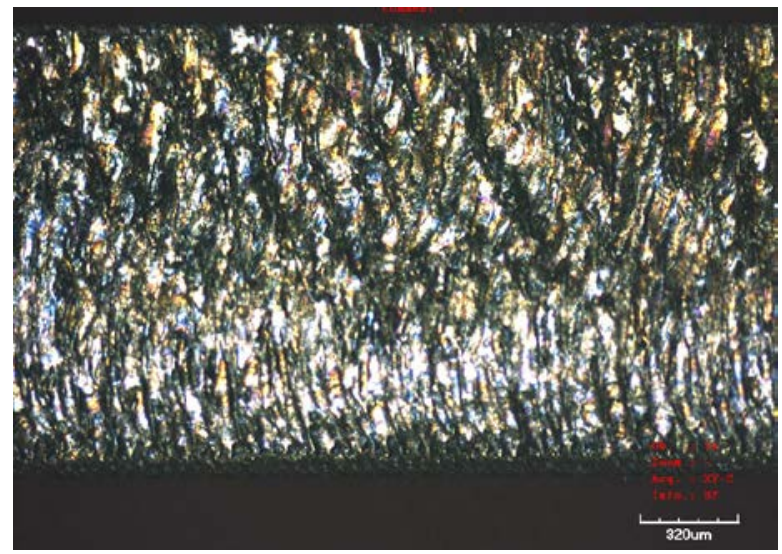

Fig. 3. Optical light micrograph of the cut edge appearance of an AISI 301LN specimen. Laser beam entered from the top side.

\begin{tabular}{|c|c|c|c|}
\hline \multirow{2}{*}{ Steel } & Edge condition & $\begin{array}{c}\text { Fatigue Limit, } \\
\sigma_{\mathrm{f}, \max }(\mathrm{MPa})\end{array}$ & $\begin{array}{c}\text { Fatigue Limit, } \\
\Delta \sigma / 2(\mathrm{MPa})\end{array}$ \\
\hline \multirow{2}{*}{ 301LN } & As cut & $515 \pm 92$ & $463 \pm 82$ \\
\cline { 2 - 4 } & Polished & $602 \pm 86$ & $542 \pm 77$ \\
\hline \multirow{2}{*}{ TWIP17Mn } & As cut & $519 \pm 23$ & $467 \pm 21$ \\
\cline { 2 - 4 } & Polished & $555 \pm 17$ & $500 \pm 15$ \\
\hline
\end{tabular}

Table 3. Fatigue limits of the investigated steels for both edge conditions.

A significant effect of the edge state is patent from the results of Table 3. Both steels have almost the same fatigue limit when as-cut specimens are considered. For the stainless steel polishing increases the fatigue limit in around $80 \mathrm{MPa}$, which represents an improvement of $17 \%$; whereas in the case of TWIP steel this proportion is only $7 \%$.

For specimens tested in the as-cut state, all the fatigue fractures initiated from the intersection between the lateral surface (i.e. the cut-edge) and the main surface, as can be seen in Fig. 4. In the case of $301 \mathrm{LN}$ polished specimens, fatigue cracks nucleated either in the lateral surface or in the intersection between the cut-edge and the main surface.

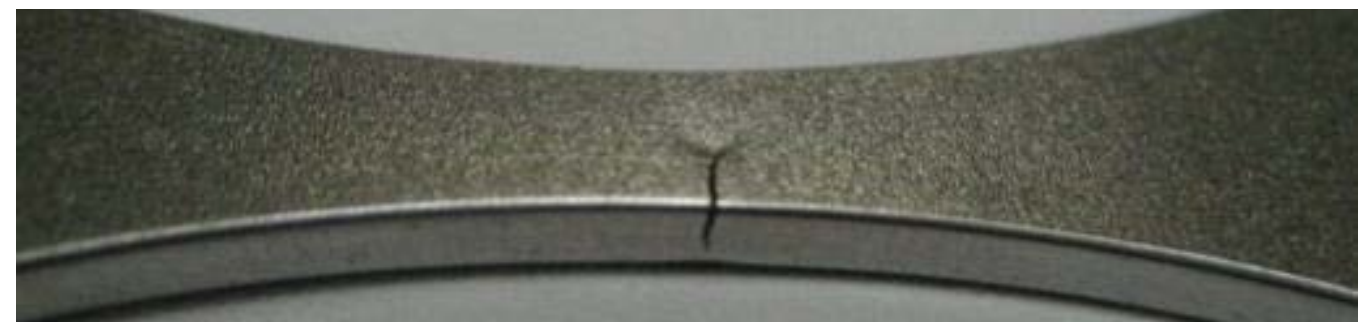

Figure 4. Fatigue crack nucleated in the intersection between the cut-edge and the main surface. 
For TWIP17Mn polished samples, fatigue cracks initiated on the main surface were observed too. A closer view (Fig. 5) revealed that, in the latter case, microcracks had nucleated from broken particles. These particles were present in an unusually high amount and were identified by EDS as titanium nitrides.

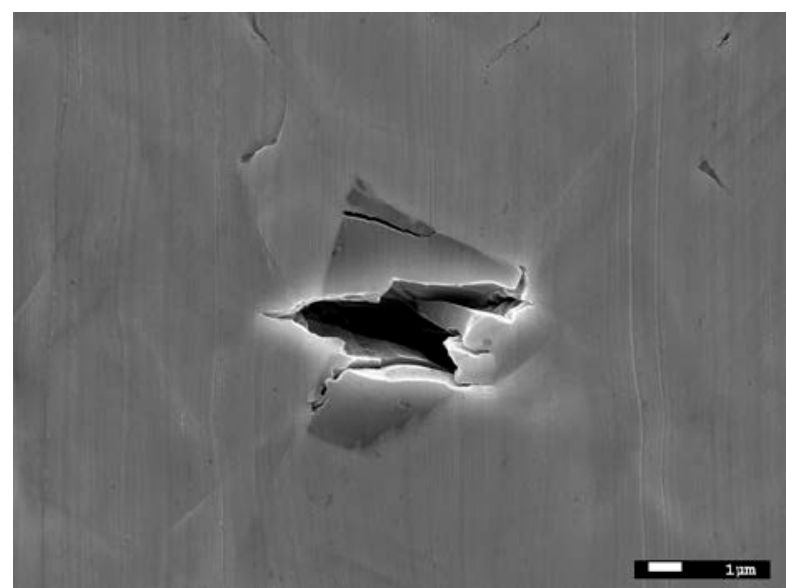

Figure 5. Microcrack nucleated from a titanium nitride in a fatigue specimen of TWIP17Mn.

Acknowledgements: To the Spanish Ministerio de Economía y Competitividad (MAT0914461) for the economic support; to Outukumpu (Finland) and Posco (South Korea) for supplying the studied steels; and to M. Clotet and G. Sixto for their experimental work contribution.

\section{REFERENCES}

[1] Advanced High Strength Steel (AHSS) Application Guidelines Version 3. Int. Iron and Steel Institute, Committee on Automotive Applications. September 2006

[2] Lyden S.: "Steel" Yourself for the Future of Truck Bodies

Work Truck Magazine, September 2012

[3] Thomas D.J.; Whittaker, M.T.; Bright, G.W.; Gao, Y.:

The influence of mechanical and $\mathrm{CO}_{2}$ laser cut-edge characteristics on the fatigue life performance of high strength automotive steels

J Mat Proc Tech 211 (2011) pp. 263-274

[4] Meurling, F.; Melander, A.; Linder, J., Larsson, M.:

The influence of mechanical and laser cutting on the fatigue strengths of carbon and stainless sheet steels

Scandinavian Journal of Metallurgy 30 (2001) pp. 309-319

[5] Karjalainen, L.P.; Taulavuori, T.; Sellman, M.; Kyröläinen, A.:

Some Strengthening Methods for Austenitic Stainless Steels

Steel research int. 79 (2008) No. 6, pp. 404-412

[6] Karaman, A. Sehitoglu, A. J. Beaudoin, Y. I. Chumlayakov, H. J. Maier, C. N. Tomé: Modeling the deformation behavior of Hadfield steel single and polycrystals due to twinning and slip

Acta Mater. 48 (2000) 18-19, pp. 2031-2047

[7] Lin, S-K.; Lee, Y-L.; Lu, M-W.:

Evaluation of the staircase and the accelerated test methods for fatigue limit distributions

Int J Fatigue 23 (2001) pp. 75-83 